\title{
Epidermal necrosis due to vasculitis in rickettsial fever
}

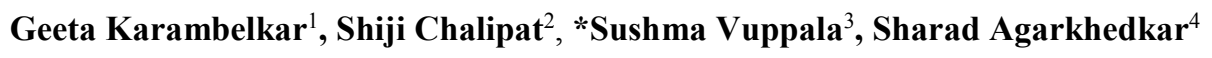

Sri Lanka Journal of Child Health, 2015; 44(2): 119-120

(Key words: epidermal necrosis, vasculitis, rickettsial fever)

\section{Introduction}

Cases of rickettsial fever have been reported in many parts of India ${ }^{1}$. Indian tick typhus is endemic in Pune region of Maharashtra ${ }^{2}$. Complications due to vasculitis in rickettsial fever include hepatitis, pancreatitis, interstitial pneumonitis, etc ${ }^{1}$. Though rare, vasculitic complications like oedema and bluish discolouration of hands and feet and epidermal necrosis are also noted ${ }^{2}$. Some purpuric lesions may enlarge to ecchymosis with gangrenous changes and may rarely progress to gangrene of the digits ${ }^{1}$. We report 2 cases of epidermal necrosis due to vasculitis with rickettsial fever.

\section{Case report}

Two boys aged 5 months and 3 years respectively were brought with the complaints of fever since 8 to 9 days and rash that appeared on $2^{\text {nd }}$ and $4^{\text {th }}$ day of onset of fever. Rash was maculopapular, present all over the body including palms and soles. Some lesions were purpuric. The 5 month old boy also had oedema over dorsum of hand and foot and bluish discolouration of 1 st and 2 nd toes of right foot that was tender on palpation. (Figures $1 \& 2$ ). The 3 year old boy also had oedema of both hands with bluish discoloration of tips of $3^{\text {rd }}$ and $4^{\text {th }}$ fingers of right hand, which was gradually progressive and painful (Figures $3 \& 4$ ). On examination, both children were haemodynamically stable and all peripheral pulses were palpable. Oxygen saturation of all four limbs was more than $97 \%$. On abdominal examination, both children had hepatosplenomegaly. Other systemic examinations were within normal limits.

${ }^{1}$ Professor in Paediatrics, ${ }^{2}$ Asst. Professor in Paediatrics, ${ }^{3}$ Department of Paediatrics, D.Y. Patil University, Pune, ${ }^{4}$ Professor and Head of the Department of Paediatrics, Dr. D. Y. Patil Medical Hospital and Research Centre, Pimpri, Pune, India

*Correspondence: dr.sushmavuppala@gmail.com

(Received on 3 June 2014: Accepted after revision on 18 July 2014)

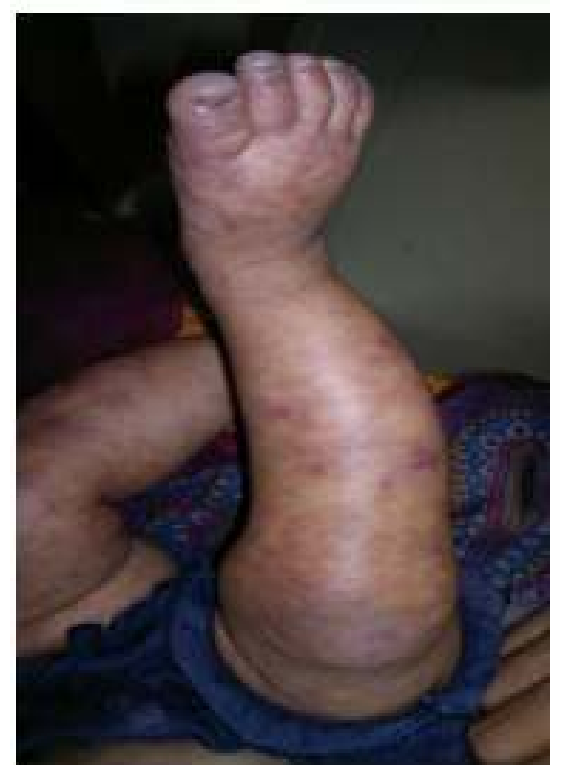

Figure 1: Maculopapular rash, oedema and bluish discolouration of foot

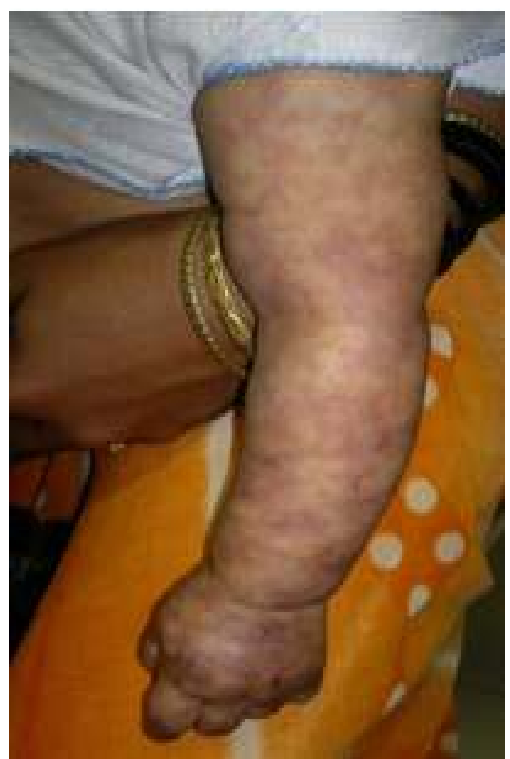

Figure 2: Maculopapular rash, oedema and bluish discolouration of hand 


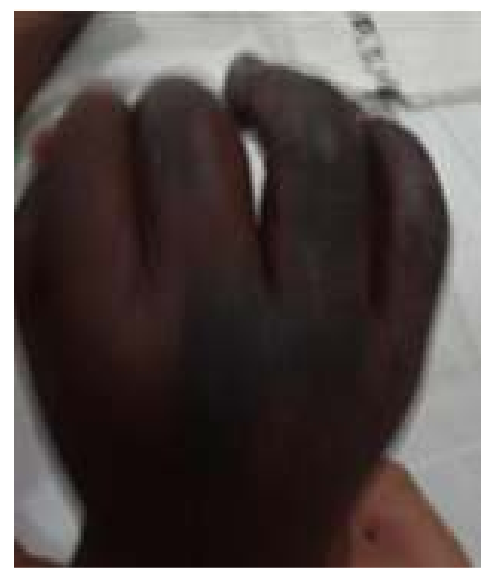

Figure 3: Oedema of hand

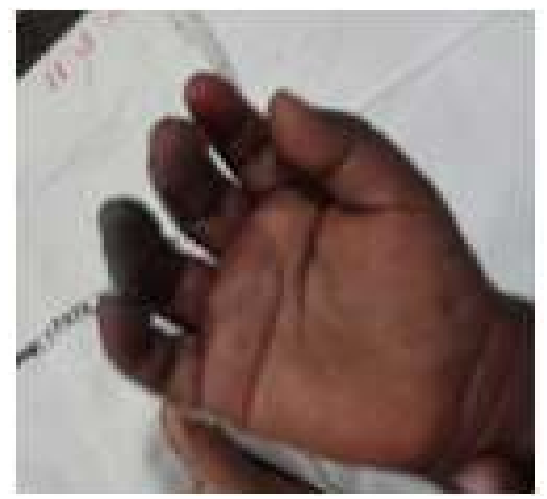

Figure 4: Bluish discolouration of fingers

In both cases haemoglobin was $<10 \mathrm{~g} / \mathrm{dl}$, total white blood cell count showed leucocytosis and the urine examination was normal. Weil Felix test was positive for OX 19 antigen (titre 1:240) in the 5 month old boy and antigen OX-K (titre 1:120), OX-19 (titre 1:320), OX-2 (titre 1:160) were positive in the 3 year old boy. Rickettsial IgM and IgG were positive in both cases. Bleeding time, clotting time and platelet count were within normal limits. Liver and renal function tests were normal. Coagulation profile was normal and sickling test was negative. Chest $\mathrm{x}$-ray was normal. Arterial Doppler of upper and lower limbs in both cases were reported as normal. Ultrasonogram (USG) of abdomen and pelvis was normal and the 2D Echo was normal. Both children were treated with chloramphenicol and anti-inflammatory medications. The superficial skin over the discoloured areas got desquamated and gradually lesions healed (Figure 5).

\section{Discussion}

There should be a high index of suspicion of rickettsial fever in cases with fever and rash that is maculopapular, petechial or purpuric involving palms and soles ${ }^{1}$.

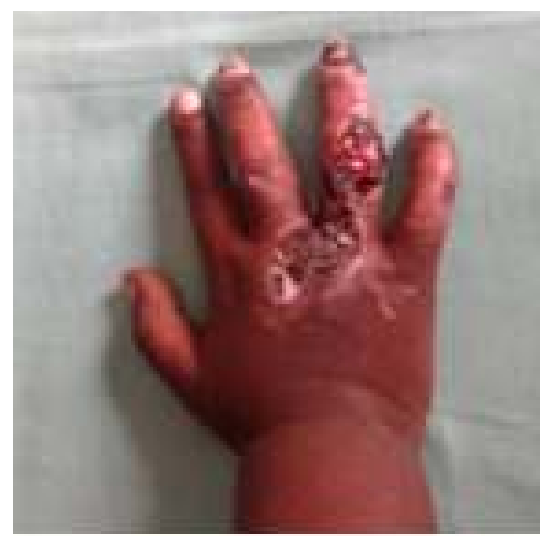

Figure 5: Desquamated healing lesion

Proliferation of rickettsia within endothelial cell cytoplasm leads to lymphohistiocytic vasculitis of small venules and capillaries resulting in petechial skin lesions and microvascular leakage, tissue hypoperfusion and possibly end organ ischaemic injury. Small and large vessels rarely become completely obliterated by thrombosis, leading to tissue infarction or haemorrhagic necrosis ${ }^{3}$. Severe vascular obstruction secondary to rickettsial vasculitis and thrombosis is infrequent but can result in epidermal necrosis of digits as seen in the 2 cases $^{3}$.

Complications observed due to rickettsial vasculitis and hypoperfusion are hepatitis, pancreatitis, epidermal necrosis and gangrene ${ }^{2}$. Gangrene is seen in $4 \%$ cases of Rickettsia prowazekii infection ${ }^{4}$.

\section{References}

1. Rathi N Rathi A. Rickettsial infection: Indian Perspective, Indian Pediatrics 2010; 47(2): 15764.

http://dx.doi.org/10.1007/s13312-010-0024-3 PMid:20228429

2. Padbidri VS, Rodrigues JJ, Shetty PS. Tickborne rickettsiosis in Pune district, Maharashtra, India. International Journal of Zoonoses 1984; 11(1): 45-52.

PMid:6500861

3. Reller ME, Stephen J. Rickettsial infection. In Kliegman RM, Stanton BMD, N, Behrman RE, editors. Nelson Textbook of Pediatrics $19^{\text {th }}$ ed. Philadelphia: Elsevier; p 1038 - 43.

4. Walker DH, Raoult D: Rickettsia prowazekii, Mandel, Douglas and Bennet's Principles and Practice of Infectious Diseases, $7^{\text {th }}$ ed. Philadelphia: Elsevier; p 2522 